trace is visible of this effect, making it clear that the particles are not hollow in the centre, as might be inferred from Fig. 3.

Beryllium films allow much clearer micrographs to be obtained of virus and similar particles than when they are carried on collodion films, owing to the greater background scattering given by the latter. Particle-size determination is thereby made more accurate, especially when side-by-side aggregations are obtainable, as in Fig. 3. It is observed, however, that the virus exposed to the electron beam rapidly becomes clouded over and all definition is lost in a few minutes. It is probably as much due to this effect as to the greater background scattering, that the lattice structure in crystalline fragments of viruses has not previously been observed with collodion-supported preparations. The nature of this contamination has been discussed elsewhere?

${ }^{1}$ Markham, R., and Smith, K. M., Nature, 157, 300 (1946).

- Carlisle, C. H., private communication.

'Price, W. C., and Wyckoff, R. W. G., Nature, 157, 764 (1946). - Markham, R., Smith, K. M., and Wyckoff, R. W. G., Nature, 159,

- Unpublished data.

- Hast, N., Nature, 159, 354 and 370 (1947).

'Cosslett, V. E., Electron Microscope Conference, Leeds, Sept. 1947, in the press.

\section{DISCHARGE TUBE FOR NUCLEAR REACTIONS WITH IMPROVED YIELD}

$\mathrm{N}$ an article on a "Discharge Tube for Nuclear Reactions with Improved Yield" (Elektrotechnicky Obzor (Prague), 36, No. 14, 266 ; 1947), I have described a new discharge tube which, besides giving a better yield and minimized target heating, has the advantage that the acceleration of the particles is effected in two stages: acceleration by means of 100 $300 \mathrm{kV}$. with a current consumption of the order usual for normal discharge tubes using 1-2 MV., and a following principal acceleration by a tension of some megavolts with a current consumption less than five hundredth of usual values.

As shown in the accompanying diagram, particles leaving the ion source 1 are subjected to the first acceleration before the electrode 2 , and then they are highly accelerated between the electrodes 2, 2"; $2^{\prime \prime}, 2^{\prime \prime \prime} ; 2^{\prime \prime \prime}, 3$. The highly accelerated particles go through the target, which is $5 \times 10^{-4} \mathrm{~cm}$. thick. Only a small number of them produce nuclear reactions or are diverted from their direct paths. Through the scattering by electrons, the other particles give up that part of their kinetic energy which they have obtained by the first acceleration, and thus heat the target. Then they are retarded into the electrostatic field between the electrodes 3,$5 ; 5^{\prime}, 5^{\prime \prime} ; 5^{\prime \prime}, 6$ to such a degree that they enter into the recombination place 6 with little kinetic energy. After recombination, they are sucked from 6 by a high-vacuum pump into a reservoir or through a high-vacuum pipe of sufficient length back into the ion-source 1. The condensers 7 serve to divide the tension. At the same time they hold it constant, as does condenser 8 . The tension for the first acceleration is brought to connectors 9 and that for the chief acceleration to connectors 10.

The greater part of my article relates to the theoretical calculations of the energy conditions in the new tube, and six numerical examples are provided. In order to produce $10^{11}$ neutrons per second from beryllium $5 \times 10^{-4} \mathrm{~cm}$. thick by deuterons, we need for the first acceleration the current-intensity $800 \mu \mathrm{A}$. at a tension of $300 \mathrm{kV}$., and for the chief acceleration $0 \cdot 28 \mu \mathrm{A}$. at $2 \cdot 70 \mathrm{MV}$. If we raise the tension for the chief acceleration to $9.90 \mathrm{MV}$., the current consumption is $0.016 \mu \mathrm{A}$. for the chief acceleration and $800 \mu \mathrm{A}$. at a tension $100 \mathrm{kV}$. for the first acceleration. In the usual discharge tubes with a massive target, we need under the same conditions a current intensity not less than $150 \mu \mathrm{A}$. at $3 \mathrm{MV}$. and not less than I6 $\mu \mathrm{A}$. at $10 \mathrm{MV}$.

Thus the reduction of current consumption for the chief acceleration is very considerable. Also the target heating is minimized. In spite of this, its cooling (by radiation) is the most difficult problem of the new tube. This point will probably decide whether it will be advantageous to construct the tube.

The principal idea of the new tube, namely, to regain the kinetic energy of the highly accelerated particles by means of retardation in the electrostatic field, can be used with great advantage in the construction of other tubes for nuclear physics. In those, and not in the tube discussed, lies the practical use and importance of the scheme.

JARoslav Padhner

\section{WAR-TIME RHEOLOGICAL INVEST- IGATIONS FOR THE BRITISH ARMED SERVICES}

A

GENERAL meeting of the British Rheologists' Club was held at the Royal Society of Arts on December 17, when papers on war-time rheological investigations were read by Dr. A. S. C. Lawrence (Navy). Mr. A. G. Ward (Army) and Dr. E. W. J. Mardles (Royal Air Force). Dr. A. S. C. Lawrence spoke on the experiments done subsequent to the lecture on rheology and Naval problems by Sir Charles Goodeve in 1943 ("Essays in Rheology", Pitman, 1947), and by means of photographs he described the icing of ships in the North Atlantic and methods employed for de-icing. Dr. Lawrence continued with the problem of sea-water - fuel emulsions and fundamental work carried out in connexion with it.

Mr. A. G. Ward spoke on researches carried out with regard to the elasticity and plasticity characteristics of various propellants and of methods of rheological measurement involved, including those of resonance and penetration. Dr. E. W. J. Mardles mentioned rheological problems involved in the highspeed and high-altitude flight of aircraft, when temperatures so low as $-80^{\circ} \mathrm{C}$. are sometimes reached, with consequent development of tendency in 
materials to fracture. Methods of measurement of the consistency of greases and lubricants at low temperatures had been worked out and were briefly described.

Mr. A. de Waele (in the chair), in opening the discussion, remarked on the wide range of problems dealt with successfully by the rheologist; among the subjects discussed by the meeting were the dispersion phenomena of cellulose derivatives in organic media, the movement of spheres in emulsions and non-Newtonian liquids in general (Stokes' law is not usually applicable), rigidity-thixotropy, and the penetration of clays and other soft solids by piles and other penetrometers. Dr. A. W. Skempton described some recent experiments on clay movement, supporting the findings of A. S. C. Lawrence that the movement of a droplet in a fuel - sea-water emulsion is accompanied by vortex movement extending to at least ten diameters, and of E. W. J. Mardles that similar movements have been observed in thickened liquids during penetration by spheres, disks, rods or cones. The general movement over a wide range of the system, such as when a grease is penetrated by a solid body, may account for the finding of E. W. J. Mardles that the volume displaced by a penetrometer of given weight over a period of time is more or less independent of the shape, and characteristic of the material.

\section{SOCIAL STUDIES OF THE ELDERLY}

\section{BY ELEANOR FRENCH}

T is interesting to watch the emphasis slowly shifting in the sphere of social welfare to the elderly and their needs and problems, as the relentless march of time forces the effects of our ageing popula. tion upon our notice. In 1901 there were 2,408,426 persons in Great Britain over sixty years of age; in 1946 there were $6,587,000^{1}$, and the assumption in the Beveridge Report is that by 1971 there will be $9,576,000$ men over sixty-five and women over sixty in Britain2.

The two extremes of life thus assume a new importance, and the increasing claims of the ageing must not be met at the expense of the young; but to say this does not mean that those claims should be ignored. The publication of "Old People" by the Trustees of the Nuffield Foundation ${ }^{3}$ earlier in the year aroused much interest; this has been followed. by a further survey of a particular district : "Old People's Welfare on Merseyside", and in June the British Medical Association published a report on the care and treatment of the elderly and infirm. These three documents give a clear picture of the present conditions in which the elderly are living and make recommendations for improving and supplementing them.

One of the most urgent needs for them (as for everyone else) is better housing: there appears to be little question that old people are badly underhoused, and according to Dr. Elsas ${ }^{5}$, in 1939, given a ratio of forty dwellings per hundred adults, the 3.7 million persons over sixty-five should have had 1.5 million dwellings; but there were actually at that time only half a million dwellings in England and Wales consisting of one or two rooms. Conditions have certainly not improved since then, and the Nuffield Survey" recommends "that $5 \%$ of the houses in any community should be such as are suited to the special needs of old people. ...."

But though 95 per cent of old people live in private houses $^{3}$, the remaining 5 per cent live in institutions, whether public or private, and here, too, conditions are often unsatisfactory. Institutions under the local authority are often vast old-fashioned 'barracks' : for example, in four of these institutions in Liverpool and Birkenhead on one night in February 1946 there were 2,312 " old people of pensionable age : "The sight of a dining room seating 300 , a huge dormitory with 110 beds ... is most depressing"“. Old people and children seem to need very similar conditions for their welfare and happiness, and the Report of the Curtis Committee regards large institutions as quite unsuitable for young children also. It is good news that local authorities, or rather "welfare author. ities' as they will be called, have been given power to establish special homes for the aged to house between twenty and thirty.

Adequate medical aids, another pressing want of the aged, will be available under the new National Health Service. When these and other material needs have all been met, there still remain those of the spirit, for old age is apt to bring loneliness, a sense of uselessness, and boredom. Much could be done to remedy these : Dr. Vischer, for example, at Basel, has his homes for the aged attached to the municipal hospital, and their inmates are offered, if they wish, suitable types of work in the clinics and dispensary, for which they are paid a small fee $\theta^{6}$. Such a scheme encourages the old people and gives them a sense of still being useful members of a community, and at the same time it helps the hospital to solve its staff problem. Old age tends to isolate the individual from the main stream of life, but at the same time full utilization of his remaining powers is needed for the benefit of the community of which the aged form an increasing part.

${ }^{2}$ Registrar General's figures.

2 Report of the Committee on the Care and Treatment of the Elderly and Infirm, Brit. Med. J. (June 21, 1947).

"“old People" (Nuffeld Foundation).

" "Old People's Welfare on Merseyside" (University of Liverpool, Social Science Department).

'Elsas, M. J., "Housing and the Family", 91.

"Vischer, A. L., "Old Age".

\section{FUEL ECONOMY IN SWITZERLAND}

$T$

HE World Power Conference is issuing reports on war-time fuel-saving methods in many States. Obviously these differ widely.

The problem in Switzerland* was given a particular interest by clear-cut circumstances and limitations. That country lacks substantially all native solid or liquid fuel resources except wood, and this plays an insignificant part. The only freely available source is hydro-electric power, and this provides only a minor part of the need. Furthermore, it is essentially seasonal in supply, being dependent on the variable flow of streams. Summer is the principal season for the production of water-power, whereas winter is the time when power is in greatest demand. Available storage facilities are inadequate to compensate for this disparity. At most, available water-power provides for the needs for lighting and motive power,

- Reports on Fuel Economy since 1939. Swiss National Committee Pp. 20. (Central Office of World Power Conference, 201-202 Grand Buildings, Trafalgar Square, London, W.C.2.) 18, net. 